\title{
Effects of a fruit-vegetable dietary pattern on oxidative stress and genetic damage in coke oven workers: a cross-sectional study
}

\author{
Zheng Xie ${ }^{1}$, Haijiang Lin ${ }^{2}$, Renfei Fang ${ }^{1}$, Weiwei Shen ${ }^{2}$, Shuguang $\mathrm{Li}^{3}$ and Bo Chen ${ }^{3 *}$
}

\begin{abstract}
Background: Coke oven workers (COWs) are exposed to high level of genotoxic chemicals that induce oxidative stress and genetic damage. The dietary intake of certain types of foods may reverse these effects.

Methods: We conducted a cross-sectional study with 51 topside COWs, 79 other COWs, and 67 controls, to assess the effects of dietary patterns on oxidative stress and genetic damage.

Results: Compared to the controls, both topside and other COWs had significantly higher urinary 1-hydroxypyrene levels, serum oxidant levels [malondialdehyde, (MDA)], and genetic damage [micronucleus (MN) frequency \& 8-oxo-2'-deoxyguanosine (8-OH-dG)], but lower antioxidant levels [superoxide dismutase (SOD) and glutathione peroxidase, (GPX)]. The fruit-vegetable (FV) dietary pattern was positively correlated with serum SOD levels and negative correlated with serum MDA, MN frequency, and urinary 8-OH-dG. COWs with an FV patter in the highest quartile (Q4) had significantly increased antioxidant levels (SOD and GPX) and decreased oxidant levels (MDA) and genetic damage (MN frequency and 8-OH-dG) than those with an FV pattern in the lowest quartile (Q1).
\end{abstract}

Conclusion: Compared to control subjects, COWs had increased oxidative stress and genetic damage. A FV dietary pattern may reverse oxidative stress and genetic damage in COWs.

Keywords: Coke oven workers, 1-hydroxypyrene (1-OHP), Oxidative stress, Genetic damage, Fruit-vegetable dietary pattern

\section{Background}

Coke oven workers (COWs) are exposed to a wide variety of toxic chemicals, including polycyclic aromatic hydrocarbons (PAHs) and benzene series (benzene, toluene and xylenes) [1], which are potentially carcinogenic [2,3]. Epidemiologic studies have shown that COWs have increased incidence of pulmonary cancer due to exposure to these genotoxic chemicals [4].

The compound 8-oxo-2'-deoxyguanosine (8-OH-dG) is a product of DNA oxidation [5]; high exposure to PAHs is associated with high urinary levels of $8-\mathrm{OH}-\mathrm{dG}$ [6-8]. At the chromosomal level, the micronucleus (MN) assay detects both clastogenic and aneugenic potentials of genotoxic agents [9]. The $\mathrm{MN}$ assay in peripheral

\footnotetext{
* Correspondence: chenb@fudan.edu.cn

${ }^{3}$ Key Laboratory of Public Health Safety of Ministry of Education, School of Public Health, Fudan University, 138 Yixueyuan Road, Shanghai 20032, P. R. China

Full list of author information is available at the end of the article
}

blood lymphocytes has been extensively used in Chinese COWs to evaluate chromosomal damage $[7,10,11]$.

Oxidative stress is one of the key factors that contributes to genetic damage [12]. Oxidative stress, which results from an imbalance between reactive oxygen species (ROS) formation and antioxidant activity, leads to damaged lipids, proteins, and cellular macromolecules [13]. In addition to 8-OH-dG [5], malondialdehyde (MDA), superoxide dismutase (SOD), and glutathione peroxidase (GPx) are generally measured to assess oxidation-reduction imbalances [14]. Chinese COWs have been reported to have higher levels of oxidants and lower levels of antioxidants than controls [15].

There are two main methods to reduce oxidative stress and genetic damage in COWs: reduce toxin exposure and inhibit the toxic action of genotoxic chemicals. Fruit and vegetable (FV) consumption has been shown to prevent certain types of cancer [16]. Phytochemicals in FVs may inhibit the genotoxic action of food-borne carcinogens [17]. 
It has been reported than an adequate intake of fruits, vegetables, and vitamin $C$ is protective in pregnant women exposed to PAHs [18].

Even though carcinogen exposure in COWs is mainly air-borne as opposed to food-borne, we hypothesize that the consumption of FVs in COWs inhibits the genotoxic action of air-borne carcinogens. We performed a crosssectional study with COWs from a large coking plant in Southern China. Factor analyses were performed to explore the associations between different dietary patterns and parameters of oxidative stress and genetic damage.

\section{Methods}

\section{Study design and subjects}

This study was conducted in September 2009 in a large coking plant in Southern China. The coke oven battery is hollow in the middle; coke oven emissions (COEs) are released when the lid or side door of the coke oven is opened or when the oven battery is not properly sealed. Exposure to COEs depends on several factors including the battery location, i.e., top, side, or bottom of the oven. Topside oven workers are usually exposed to the highest COE levels. In this study, the exposed group consisted of topside workers and other COWs, and the control group consisted of office workers, cafeteria servers, or other members of the coking plant. All COWs were males; therefore, we only selected male subjects for the control group. The working area of the control group was approximately 450 meters away from the coking plant. The control group had a less rigorous working schedule compared to that of COWs.

In this study, we invited 262 workers from the coking plant to participate. Among them, 21 COWs and 16 controls refused to participate, $14 \mathrm{COWs}$ and $10 \mathrm{con}$ trols did not provide any blood samples, and 2 COWs and 2 controls did not provide any urine samples. Therefore, 197 subjects were enrolled, including 51 topside COWs, 79 other COWs, and 67 controls. No information was obtained from the 37 subjects who refused to participate. There were no significant differences in demographic characteristics between the participating subjects and the 16 COWs and 12 controls who did not provide any blood or urine samples.

Subjects completed a detailed questionnaire on demographic characteristics such as age, BMI (normal, $\leq 25$; overweight, >25), education level (e.g., high school or below, college, or above), cigarette smoking (nonsmoker or smoker), alcohol consumption (nondrinker or drinker), working hours per day, and years of service. All subjects provided urine and blood samples.

The study was performed with approval from local authorities and the Ethics Committee of School of Public Health at Fudan University, China. Informed consent was obtained from each subject.

\section{Food frequency questionnaire (FFQ)}

Dietary intake information was obtained from a FFQ based on the 2002 China National Nutrition and Health Survey (CNNHS) [19], with slight modifications. The subjects were instructed to report the consumption frequency and amount of 25 food items (as opposed to 33 food items in the CNNHS's FFQ) within the past three months (as opposed to one year in the CNNHS's FFQ). Consumption frequency was categorized as daily, weekly, and monthly. Daily consumption of each food item was derived by dividing the weekly consumption by 7 and the monthly consumption by 30 . The FFQ was compared with two 24-h recalls (one day 24-h recall at the beginning of a three-month period and one day 24-h recall at the end of the three-month period) performed with 96 adults from Shanghai (median age: 43 y). The results revealed the following intra-class correlation coefficients for macronutrients: total energy, 0.46; total protein, 0.59 ; total fat, 0.38 ; carbohydrate, 0.61 ; dietary fiber, 0.55 ; and calcium, 0.78 .

\section{Measurement of urinary 1-hydroxypyrene (1-OHP) levels} All participating subjects provided a urine sample $(20 \mathrm{ml})$. Urinary 1-OHP levels were measured by HPLC [20]. The detection limit of 1-OHP was $0.15 \mathrm{ng} / \mathrm{ml}$. In this study, 1-OHP was detected in all urine samples. Urinary 1-OHP levels were adjusted for urinary creatinine excretion ( $\mu \mathrm{mol} / \mathrm{mol}$ creatinine).

\section{Measurement of oxidative stress}

Blood samples $(3 \mathrm{ml})$ were collected in test tubes devoid of anticoagulant and centrifuged at $1,500 \mathrm{rpm}$ for $10 \mathrm{~min}$. The resulting serum was used to measure SOD, GPx, and MDA levels by enzyme-linked immunosorbent assay (ELISA) (Liansuo Biological Technology Co., Ltd, Shanghai, China).

\section{Measurement of 8-OH-dG levels}

Urinary 8-OH-dG levels were measured by ELISA (Liansuo Biological Technology Co., Ltd). Urinary 8-OH-dG levels were adjusted for creatinine excretion ( $\mu \mathrm{mol} 8-\mathrm{OH}-\mathrm{dG} / \mathrm{mol}$ creatinine).

\section{MN frequency analysis}

The cytokinesis-blocked micronucleus (CB-MN) assay was performed as previously described [21]. For the evaluation of chromosomal damage, one scorer blindly analyzed the MN frequencies in 1,000 bi-lymphocytes from each culture.

\section{Statistical analyses}

The SPSS 12.0 (SPSS Inc., Chicago, IL, USA) software package was used for data processing and statistical analyses. Urinary 1-OHP and 8-OH-dG levels were natural log- 
transformed. All statistical tests were two-sided $(\alpha=0.05)$. One way ANOVA and chi-square analyses were used to evaluate differences in demographic characteristics and between exposed and control groups. Linear regression models were used to assess the effects of food frequencies and dietary patterns on parameters of oxidative stress and genetic damage.

Factor models using principle components analyses were used to identify dietary patterns. The factors were orthogonally rotated to derive non-correlated factors. In this study, 13-15 factor solutions were specified, and eigenvalues and factor loadings were assessed. Following these analyses, a four-factor solution was selected. Factor loadings were calculated for each food group across the four factors (dietary patterns). For each dietary pattern, a factor score for each subject was calculated by adding the intakes of all food groups weighted by their factor loadings. Each factor was divided into quartiles; sample characteristics were compared between the highest $(\mathrm{Q} 4)$ and lowest quartiles (Q1) by analysis of covariance (for means) and chi-square test (for frequencies).

\section{Results}

Table 1 shows the demographic characteristics of all participating subjects. Topside workers were younger than control subjects and other COWs. Topside and other COWs had shorter years of service compared to the controls. No other significant differences in demographic characteristics were obtained between COWs and controls.

Table 1 Demographic characteristics of coke oven workers (COWs) and controls

\begin{tabular}{|c|c|c|c|}
\hline Characteristics & $\begin{array}{l}\text { Controls } \\
(n=67)\end{array}$ & $\begin{array}{l}\text { Topside COWs } \\
(\mathrm{n}=51)\end{array}$ & $\begin{array}{l}\text { Other COWs } \\
(n=79)\end{array}$ \\
\hline Age (years) ${ }^{a}$ & $38.1(7.5)$ & $35.5(8.3)^{*}$ & $37.8(8.2)$ \\
\hline \multicolumn{4}{|l|}{$\mathrm{BMI}\left(\mathrm{kg} / \mathrm{m}^{2}\right)^{\mathrm{b}}$} \\
\hline$\leq 25$ & $46(69)$ & $40(78)$ & $58(73)$ \\
\hline$>25$ & $21(31)$ & $11(22)$ & $21(27)$ \\
\hline \multicolumn{4}{|l|}{ Level of education ${ }^{b}$} \\
\hline High school and below & $57(85)$ & $46(90)$ & $73(92)$ \\
\hline College and above & $10(15)$ & $5(10)$ & $6(8)$ \\
\hline \multicolumn{4}{|l|}{ Cigarette smoking $^{b}$} \\
\hline Nonsmoker & $28(42)$ & $15(29)$ & $28(35)$ \\
\hline Smoker & $39(58)$ & $36(71)$ & $51(65)$ \\
\hline \multicolumn{4}{|l|}{ Alcohol drinking $^{b}$} \\
\hline Nondrinker & $25(37)$ & $18(35)$ & $25(32)$ \\
\hline Drinker & $42(63)$ & $33(65)$ & $54(68)$ \\
\hline Working hours per day ${ }^{a}$ & $8.4(1.1)$ & $7.6(0.7)$ & $7.7(0.8)$ \\
\hline Years of service ${ }^{a}$ & $10.2(3.4)$ & $6.9(2.3)^{* * *}$ & $7.6(1.9)^{* * *}$ \\
\hline
\end{tabular}

${ }^{*} P<0.05,{ }^{* * *} P<0.001$ vs. control group.

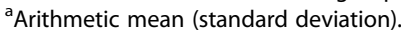

${ }^{\mathrm{b}}$ Number (\%).
COWs, especially topside workers, had significantly higher urinary 1-OHP levels than the controls (Table 2), indicating that COWs were exposed to high levels of PAHs and other COEs. Compared to the controls, both topside COWs and other COWs had significantly lower levels of antioxidants (SOD and GPx) and increased oxidant levels (MDA) and genetic damage (MN frequency and 8-OH-dG; Table 2).

Four main dietary patterns were identified by factor analysis: a rice-noodle pattern (Pattern 1), an FV pattern (Pattern 2), a high protein food pattern (Pattern 3), and a snack-sugar pattern (Pattern 4; Table 3). Individual factor loadings were interpreted similarly to correlation coefficients; positive values contributed the most to the factor score and negative values contributed the least to the factor score. The four major dietary patterns explained 7.7\% (Pattern 1), 7.3\% (Pattern 2), 6.7\% (Pattern 3), and $4.9 \%$ (Pattern 4 ) of the variance in dietary intake. Altogether, the four factors explained $26.6 \%$ of the variance in dietary intake.

Multivariable regression models were used to assess the effects of different food frequencies and dietary patterns on oxidative stress and genetic damage (Table 4). The adjusted regression was conducted by incorporating all covariates into the model, which included age, BMI, level of education, cigarette smoking, alcohol consumption, working hours per day, years of service, urinary 1-OHP levels, and exposure group (controls, other COWs, and topside COWs).

In the food frequency analysis, the consumption frequency of each food item was dichotomized before being incorporated into the regression model. Daily fruit consumption was associated with significantly higher antioxidant levels (SOD) and lower oxidant levels (MDA) and genetic damage (8-OH-dG) compared to weekly or monthly fruit consumption, both in crude and adjusted models (Table 4). Similar results were obtained with dark vegetable consumption (positively correlated with high GPx levels, and negatively with MN frequency and 8-OH-dG) and light vegetable consumption (positively correlated with high SOD levels, and negatively with MDA and 8-OH-dG).

In the dietary pattern analysis, only the FV pattern was associated with increased antioxidant levels (SOD) and decreased oxidant levels (MDA) and genetic damage (MN frequency and 8-OH-dG), both in the crude and adjusted models (Table 4). High serum levels of GPx were positive correlated with the FV pattern in the adjusted model; however, the results were not significant $(P<0.1)$. Similarly, high $\mathrm{MN}$ frequency was positively correlated with the high protein food pattern in both the crude and adjusted models $(P<0.1)$.

To clearly demonstrate the effects of FV intakes, oxidative stress and genetic damage were compared amongst 
Table 2 Exposure levels, oxidative stress, and DNA damage in coke oven workers (COWs) and controls

\begin{tabular}{|c|c|c|c|}
\hline Parameters & $\begin{array}{l}\text { Controls } \\
(n=67)\end{array}$ & $\begin{array}{l}\text { Topside COWs } \\
(n=51)\end{array}$ & $\begin{array}{l}\text { Other COWs } \\
(n=79)\end{array}$ \\
\hline \multicolumn{4}{|l|}{ Exposure levels } \\
\hline 1-OHP( $\mu \mathrm{mol} / \mathrm{mol}$ creatinine $)^{\mathrm{a}}$ & $0.6(0.2-1.9)$ & $6.5(2.9-10.3)^{* * *}$ & $2.4(1.1-5.7)^{* * *}$ \\
\hline \multicolumn{4}{|l|}{ Oxidative stress } \\
\hline $\mathrm{SOD}(\mathrm{U} / \mathrm{mL})^{\mathrm{a}}$ & $1068.5(35.2)$ & $753.7(60.9)^{* * *}$ & $821.8(47.1)^{* * *}$ \\
\hline $\mathrm{GPx}(\mathrm{U} / \mathrm{mL})^{\mathrm{a}}$ & $84.2(2.3)$ & $47.8(5.6)^{* * *}$ & $55.1(3.9)^{* * *}$ \\
\hline $\mathrm{MDA}(\mathrm{nmol} / \mathrm{mL})^{\mathrm{a}}$ & $3.9(0.8)$ & $6.9(1.4)^{* * *}$ & $6.7(1.2)^{* * *}$ \\
\hline \multicolumn{4}{|l|}{ DNA damage } \\
\hline MN frequency $(\%)^{\mathrm{a}}$ & $2.2(1.8)$ & $5.1(4.7)^{* * *}$ & $4.6(5.2)^{* * *}$ \\
\hline 8-OH-dG( $\mu \mathrm{mol} / \mathrm{mol}$ creatinine $)^{\mathrm{b}}$ & $1.3(0.8-1.8)$ & $2.3(1.0-7.1)^{* * *}$ & $2.4(0.7-6.9)^{* * *}$ \\
\hline
\end{tabular}

${ }^{* * *} P<0.001$ vs. control group.

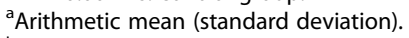

${ }^{\mathrm{b}}$ Geometric mean (95\% confidence interval).

Table 3 Factor loadings for dietary patterns in all subjects

\begin{tabular}{|c|c|c|c|c|}
\hline Food groups & Pattern 1 & Pattern 2 & Pattern 3 & Pattern 4 \\
\hline Rice & 0.81 & / & 0.21 & / \\
\hline Noodles & 0.73 & 0.19 & / & 0.21 \\
\hline Steamed buns & $\rho^{a}$ & / & / & -0.16 \\
\hline Coarse cereals & / & -0.25 & / & -0.15 \\
\hline Dark vegetables & 0.21 & 0.78 & / & / \\
\hline Light vegetables & 0.24 & 0.70 & / & / \\
\hline Mushrooms & / & / & / & / \\
\hline Legume products & / & / & 0.31 & / \\
\hline Fruit & / & 0.76 & -0.21 & 0.15 \\
\hline Eggs & 0.18 & / & / & -0.17 \\
\hline Pork & 0.20 & / & 0.61 & / \\
\hline Poultry & 0.19 & 0.20 & 0.59 & 0.20 \\
\hline Beef and mutton & / & -0.18 & / & / \\
\hline Processed meat & -0.23 & / & 0.43 & -0.23 \\
\hline Visceral organs & -0.18 & / & 0.27 & / \\
\hline Fish & 0.24 & 0.21 & / & 0.18 \\
\hline Shrimps and crabs & / & / & -0.17 & / \\
\hline Dairy products & / & 0.19 & / & / \\
\hline Beverages & -0.29 & / & -0.25 & 0.23 \\
\hline Alcohol & -0.18 & / & 0.22 & -0.27 \\
\hline Fried pasta & / & -0.23 & -0.28 & -0.27 \\
\hline Snacks and cookies & -0.15 & / & -0.26 & 0.84 \\
\hline Sugars and preserves & / & -0.19 & / & 0.61 \\
\hline Oils & 0.31 & / & / & 0.32 \\
\hline Condiments & 0.15 & / & / & / \\
\hline
\end{tabular}

${ }^{\mathrm{a} F a c t o r}$ loadings $\leq|0.15|$ were excluded for simplicity. Pattern 1: Rice-noodle pattern; Pattern 2: Fruit-vegetable pattern; Pattern 3: High protein foods; Pattern 4: Snack-sugar pattern. different exposure groups and dietary patterns. Both topside COWs and other COWs were merged together to increase statistical power. The results revealed no significant differences in the control group (Figure 1). However, COWs with an FV in the highest quartile (Q4) had significantly increased antioxidant levels (SOD and GPx) and decreased oxidant levels (MDA) and genetic damage (MN frequency and 8-OH-dG) than those with an FV pattern in the lowest quartile (Q1).

\section{Discussion}

In this study, COWs were exposed to high levels of 1-OHP, a biomarker of PAH exposure. Topside COWs had significantly higher urinary 1-OHP levels than other COWs; therefore, the topside oven is the most polluted area in a coking plant.

COWs had low levels of antioxidants (SOD and GPx) and high levels of oxidants (MDA), which contributed to an imbalance in oxidation-reduction reactions. This imbalance may be caused by a high exposure to pollutants in this study. COWs have been exposed to several PAHs and benzene series, which are converted into ROS [22,23].

Oxidative stress is a common mechanism by which some environmental chemicals induced damage. Environmental pollutants stimulate a variety toxic mechanisms at the molecular level; oxidative stress seems to be the common denominator leading to damage of cellular membranes, DNA, and, proteins [24]. As a biomarker of oxidative DNA damage, urinary 8-OH-dG levels were nearly $2 \times$ higher in the exposed workers than in the control subjects. Therefore, the COWs surveyed in this study had a higher burden of oxidative stress, which contributed to DNA damage. The fact that $\mathrm{MN}$ frequency, which is widely used in the detection of different types of genetic damage in eukaryotic cells, was significantly higher in COWs than in control 
Table 4 Food frequency and dietary pattern in association with oxidative stress and DNA damage [shown as the standardized coefficients $(\beta)$ and significance $(P)]$

\begin{tabular}{|c|c|c|c|c|c|c|c|c|c|c|}
\hline & \multicolumn{6}{|c|}{ Oxidative stress } & \multicolumn{4}{|c|}{ DNA damage } \\
\hline & \multicolumn{2}{|l|}{ SOD } & \multicolumn{2}{|l|}{ GPx } & \multicolumn{2}{|l|}{ MDA } & \multicolumn{2}{|l|}{$\overline{\mathrm{MN}}$} & \multicolumn{2}{|c|}{ 8-OH-dG } \\
\hline & $\bar{\beta}$ & $P$ & $\bar{\beta}$ & $P$ & $\bar{B}$ & $P$ & $\bar{\beta}$ & $P$ & $\bar{\beta}$ & $P$ \\
\hline \multicolumn{11}{|c|}{ Frequency of fruit consumption (daily vs. weekly+monthly) } \\
\hline Crude & 0.117 & 0.035 & 0.034 & 0.241 & -0.151 & 0.027 & -0.119 & 0.129 & -0.197 & 0.040 \\
\hline Adjusted $^{\mathrm{a}}$ & 0.104 & 0.048 & 0.031 & 0.246 & -0.143 & 0.027 & -0.138 & 0.105 & -0.178 & 0.051 \\
\hline \multicolumn{11}{|c|}{ Frequency of dark vegetable consumption (daily vs. weekly+monthly) } \\
\hline Crude & 0.098 & 0.064 & 0.122 & 0.026 & -0.144 & 0.031 & -0.212 & 0.033 & -0.205 & 0.039 \\
\hline Adjusted $^{a}$ & 0.095 & 0.065 & 0.109 & 0.041 & -0.151 & 0.025 & -0.223 & 0.036 & -0.195 & 0.042 \\
\hline \multicolumn{11}{|c|}{ Frequency of light vegetable consumption (daily vs. weekly+monthly) } \\
\hline Crude & 0.121 & 0.045 & 0.084 & 0.097 & -0.132 & 0.046 & -0.175 & 0.058 & -0.188 & 0.049 \\
\hline Adjusted $^{\mathrm{a}}$ & 0.112 & 0.052 & 0.091 & 0.092 & -0.135 & 0.045 & -0.168 & 0.066 & -0.184 & 0.051 \\
\hline \multicolumn{11}{|c|}{ Pattern 1: Rice-noodle } \\
\hline Crude & -0.037 & 0.721 & -0.082 & 0.427 & 0.054 & 0.596 & 0.115 & 0.260 & 0.038 & 0.713 \\
\hline Adjusted $^{a}$ & 0.037 & 0.396 & -0.006 & 0.885 & 0.005 & 0.951 & 0.090 & 0.357 & -0.025 & 0.686 \\
\hline \multicolumn{11}{|c|}{ Pattern 2: Fruit-vegetable } \\
\hline Crude & 0.109 & 0.041 & 0.082 & 0.106 & -0.121 & 0.031 & -0.257 & 0.017 & -0.211 & 0.031 \\
\hline Adjusted $^{\mathrm{a}}$ & 0.182 & 0.013 & 0.099 & 0.057 & -0.130 & 0.026 & -0.293 & 0.012 & -0.220 & 0.028 \\
\hline \multicolumn{11}{|c|}{ Pattern 3: High protein foods } \\
\hline Crude & -0.074 & 0.297 & -0.062 & 0.412 & -0.004 & 0.967 & 0.196 & 0.083 & 0.091 & 0.218 \\
\hline Adjusted $^{\mathrm{a}}$ & -0.057 & 0.233 & -0.033 & 0.327 & -0.021 & 0.789 & 0.174 & 0.100 & 0.079 & 0.164 \\
\hline \multicolumn{11}{|c|}{ Pattern 4: Snack-sugars } \\
\hline Crude & -0.013 & 0.900 & 0.009 & 0.932 & -0.100 & 0.330 & 0.033 & 0.696 & 0.034 & 0.739 \\
\hline Adjusted $^{a}$ & -0.031 & 0.465 & -0.036 & 0.339 & -0.072 & 0.395 & 0.040 & 0.583 & 0.072 & 0.258 \\
\hline
\end{tabular}

The food frequency comparison was within the dichotomized variables. The dietary pattern comparison was between the highest quartile subjects (Q4) and the lowest quartile subjects (Q1).

${ }^{a}$ Adjusted for age, BMI, level of education, cigarette smoking, alcohol consumption, working hours per day, years of service, urinary 1-OHP levels, and exposure group (controls, other COWs, and topside COWs).

subjects, reveals that the exposure level in this study was capable of inducing genetic damage. Studies have reported excessive oxidative stress and genetic damage in COWs with a chemical exposure level similar to or lower than that in our study $[6-8,10,11]$. The results obtained in this study suggest that it is urgent to control the exposure level to COEs in China.

The most interesting finding in our study was that the consumption of FVs enhanced antioxidant levels (SOD and GPx) and reduced oxidant levels (MDA) and genetic damage (8-OH-dG and MN frequency). In spite of well documented in vitro and in vivo evidence on the antioxidant effects of FVs, most intervention studies have failed to observe positive effects in humans [25,26]. Chang et al. [25] who evaluated the effects of 10 FV servings/ day for two weeks on endogenous DNA damage, reported no significant effects relative to the control group. Briviba et al. [26], who used an RCT design to study the effects of two daily FV servings for four weeks on the health outcomes of 64 nonsmoking male subjects, reported no significant effects relative to the control group. It should be noted that both of the above studies had limitations. In Chang's study, only 28 subjects were investigated, while in the study by Brivida et al., subjects were healthy, well-nourished, nonsmoking men. In this study, the COWs were exposed to higher levels of toxic chemicals than the subjects in Briviba's study.

Similar to our findings, two recent studies have also reported a protective effect of FVs on oxidative stress and DNA damage [18,27]. In a Korean study involving 715 pregnant women [18], there was a positive correlation between urinary MDA and 1-OHP levels and low FV consumption. In a European study involving 229 mothers and 612 newborns [27], DNA adduct levels in cord blood were negatively correlated with birth weight; the correlation was more pronounced in mothers who had low FV intakes. There are two possible reasons than can explain the results of the above two studies. Firstly, the protective effects of FVs may be attributed to the presence of vitamin $C$, vitamin $\mathrm{E}$, carotenoids including $\beta$-carotene, and phytochemicals 


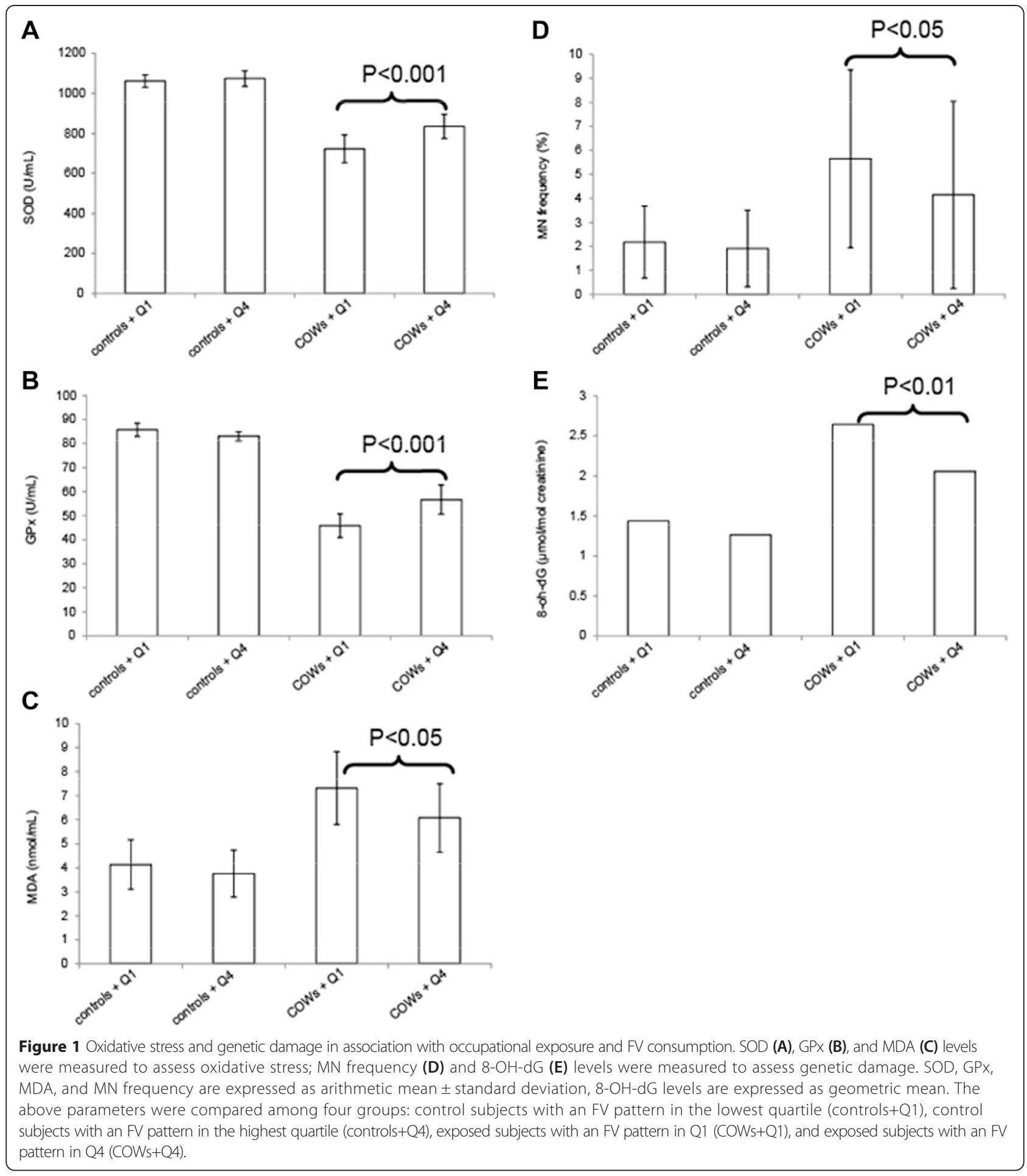

$[28,29]$. Secondly, populations with high FV intakes tend to consume low levels of meat, thereby reducing their dietary exposure to mutagenic agents (e.g., PAHs and heterocyclic amines). The second explanation is not applicable in our study, because the COWs were exposed to much higher levels of mutagenic agents from the coking environment than from their dietary sources. Thereby, our data probably revealed that the antioxidant constituents in FVs had protective effects on oxidative stress and genetic damage.

Our study had some limitations. Firstly, the use of lymphocytes as a surrogate tissue for the measurement of DNA damage is not optimal; it is possible that FVs have more physiological effects in tissues other than in circulating lymphocytes. Secondly, biological samples for 
measuring oxidative stress and genetic damage were only collected once; therefore, the results may not be reproducible. Thirdly, COWs were exposed to several types of genotoxic chemicals. Therefore, a better exposure biomarker would have been benzo[a]pyrene DNA adducts as opposed to 1-OHP. Fourthly, the FV pattern had $P$ values less than 0.05 but higher than 0.01 in certain subjects. It is apparent that the sample size in our study was too small. Future studies with larger sample size should be performed.

\section{Conclusion}

COWs were exposed to high levels of 1-OHP, a biomarker of $\mathrm{PAH}$ exposure, and had low antioxidant levels (SOD and GPx) and high oxidant levels (MDA) and genetic damage (MN frequency and $8-\mathrm{OH}-\mathrm{dG}$ ). The FV dietary pattern had beneficial effects on reversing oxidative stress and genetic damage in COWs.

\section{Abbreviations \\ 1-OHP: 1-Hydroxypyrene; 8-OH-dG: 8-oxo-2'-deoxyguanosine; BMl: Body mass index; CB-MN: Cytokinesis-blocked micronucleus; COEs: Coke oven emissions; COWs: Coke oven workers; DNA: Deoxyribose nucleic acid; ELISA: Enzyme- linked immunosorbent assay; FFQ: Food frequency questionnaire; GPx: Glutathione peroxidase; HPLC: High performance liquid chromatography; MDA: Malondialdehyde; MN: Micronucleus; ROS: Reactive oxygen species; SOD: Superoxide dismutase.}

\section{Competing interests}

The authors declare that they have no competing interests.

\section{Authors' contributions}

$\mathrm{SL}$ and $\mathrm{BC}$ contributed to conception and study design; $Z \mathrm{X}, \mathrm{HL}, \mathrm{WS}$ and $\mathrm{BC}$ contributed to acquisition of data; ZX, RF and BC performed data analysis; ZX, RF, SL and BC contributed to interpretation of data; ZX and BC contributed to manuscript writing, and $\mathrm{HL}$ and $\mathrm{SL}$ critically revised the manuscript. All authors read and approved the final manuscript.

\section{Acknowledgements}

We thank all the workers from the Coke Oven Plant for their participation and kind assistance. This work was supported by grants from the Shanghai Natural Science Foundation (11ZR1401500) and the Doctoral Fund of Ministry of Education of China (20100071120059).

\section{Author details}

${ }^{1}$ School of Public Health, Peking University Health Science Center, 38 Xueyuan Road, Beijing 100191, P. R. China. ${ }^{2} T a i z h o u$ City Center for Disease Control and Prevention, 608 The east China sea avenue, Taizhou city, Zhejiang Province 318000, P. R. China. ${ }^{3}$ Key Laboratory of Public Health Safety of Ministry of Education, School of Public Health, Fudan University, 138 Yixueyuan Road, Shanghai 20032, P. R. China.

Received: 16 September 2014 Accepted: 22 April 2015

Published online: 06 May 2015

\section{References}

1. Ciaparra D, Aries E, Booth MJ, Anderson DR, Almeida SM, Harrad S. Characterisation of volatile organic compounds and polycyclic aromatic hydrocarbons in the ambient air of steelworks. Atmos Environ. 2009:43(12):2070-9.

2. IARC, editor. Polynuclear Aromatic Compounds. Part 1. Chemicals, Environmental and Experimental Data. IARC Monogrval Carcinog Risks HumLyon. France: International Agency for Research on Cancer; 1983.

3. IARC. Overall Evaluations of Carcinogenicity: An Updating of IARC Monographs, vols 1 to 42. IARC Monogr Evalarcinog Risks Hum. Supplement 7. Lyon, France: International Agency for Research on Cancer; 1987.
4. Moolgavkar SH, Luebeck EG, Anderson EL. Estimation of unit risk for coke oven emissions. Risk Anal. 1998;18(6):813-25.

5. Valavanidis A, Vlachogianni T, Fiotakis C. 8-hydroxy-2' -deoxyguanosine (8-OHdG). A critical biomarker of oxidative stress and carcinogenesis. J Environ Sci Health Pt C-Environ Carcinog Ecotoxicol Rev. 2009;27(2):120-39.

6. Marczynski B, Rihs HP, Rossbach B, Holzer J, Angerer J, Scherenberg M, et al. Analysis of 8-oxo-7,8-dihydro-2'-deoxyguanosine and DNA strand breaks in white blood cells of occupationally exposed workers: comparison with ambient monitoring, urinary metabolites and enzyme polymorphisms. Carcinogenesis. 2002;23(2):273-81.

7. Liu AL, Lu WQ, Wang ZZ, Chen WH, Lu WH, Yuan J, et al. Elevated levels of urinary 8-hydroxy-2 -deoxyguanosine, lymphocytic micronuclei, and serum glutathione S-transferase in workers exposed to coke oven emissions. Environ Health Perspect. 2006;114(5):673-7.

8. Kuang D, Zhang W, Deng Q, Zhang X, Huang K, Guan L, et al. Dose-response relationships of polycyclic aromatic hydrocarbons exposure and oxidative damage to DNA and lipid in coke oven workers. Environ Sci Technol. 2013;47(13):7446-56.

9. Kirsch-Volders M, Decordier I, Elhajouji A, Plas G, Aardema MJ, Fenech M. In vitro genotoxicity testing using the micronucleus assay in cell lines, human lymphocytes and 3D human skin models. Mutagenesis. 2011;26(1):177-84.

10. Duan H, Leng S, Pan Z, Dai Y, Niu Y, Huang C, et al. Biomarkers measured by cytokinesis-block micronucleus cytome assay for evaluating genetic damages induced by polycyclic aromatic hydrocarbons. Mutat Res. 2009;677(1-2):93-9.

11. Dai X, Deng S, Wang T, Qiu G, Li J, Yang B, et al. Associations between 25 lung cancer risk-related SNPs and polycyclic aromatic hydrocarbon-induced genetic damage in coke oven workers. Cancer Epidemiol Biomarkers Prev. 2014;23(6):986-96.

12. Aguilera A, Garcia-Muse T. Causes of genome instability. Annu Rev Genet. 2013;47:1-32.

13. Risom L, Moller P, Loft S. Oxidative stress-induced DNA damage by particulate air pollution. Mutat Res. 2005;592(1-2):119-37.

14. Ray G, Husain SA. Oxidants, antioxidants and carcinogenesis. Indian J Exp Biol. 2002;40(11):1213-32

15. Wang F, Zhang HM, Nie JS, Xue CE, Shi YT, Niu Q. Relationship between lipid peroxidation in blood and neurobehavioral function changes in coke oven workers. Zhonghua Lao Dong Wei Sheng Zhi Ye Bing Za Zhi. 2007;25(1):15-7 (In Chinese, with abstract in English).

16. Norat T, Aune D, Chan D, Romaguera D. Fruits and vegetables: updating the epidemiologic evidence for the WCRF/AICR lifestyle recommendations for cancer prevention. Cancer Treat Res. 2014;159:35-50.

17. Schwab CE, Huber WW, Parzefall W, Hietsch G, Kassie F, Schulte-Hermann R, et al. Search for compounds that inhibit the genotoxic and carcinogenic effects of heterocyclic aromatic amines. Crit Rev Toxicol. 2000;30(1):1-69.

18. Kim H, Hwang JY, Ha EH, Park H, Ha M, Lee SH, et al. Fruit and vegetable intake influences the association between exposure to polycyclic aromatic hydrocarbons and a marker of oxidative stress in pregnant women. Eur J Clin Nutr. 2011;65(10):1118-25.

19. Li YP, He YN, Zhai FY, Yang XG, Hu XQ, Zhao WH, et al. Comparison of assessment of food intakes by using 3 dietary survey methods. Zhonghua Yu Fang Yi Xue Za Zhi. 2006;40(4):273-80 (In Chinese, with abstract in English).

20. Chen B, Hu Y, Jin T, Lu D, Shao M, Zheng $L$, et al. The influence of metabolic gene polymorphisms on urinary 1-hydroxypyrene concentrations in Chinese coke oven workers. Sci Total Environ. 2007;381(1-3):38-46.

21. Fenech M. Cytokinesis-block micronucleus cytome assay. Nat Protoc. 2007;2(5):1084-104.

22. Fu PP, Xia Q, Sun X, Yu H. Phototoxicity and environmental transformation of polycyclic aromatic hydrocarbons (PAHs)-light-induced reactive oxygen species, lipid peroxidation, and DNA damage. J Environ Sci Health Pt C-Environ Carcinog Ecotoxicol Rev. 2012;30(1):1-41

23. Singh MP, Reddy MM, Mathur N, Saxena DK, Chowdhuri DK. Induction of hsp70, hsp60, hsp83 and hsp26 and oxidative stress markers in benzene, toluene and xylene exposed Drosophila melanogaster: role of ROS generation. Toxicol Appl Pharmacol. 2009;235(2):226-43.

24. Poljsak B, Fink R. The protective role of antioxidants in the defence against ROS/RNS-mediated environmental pollution. Oxid Med Cell Longev. 2014;2014:671539. 
25. Chang JL, Chen G, Ulrich CM, Bigler J, King IB, Schwarz Y, et al. DNA damage and repair: fruit and vegetable effects in a feeding trial. Nutr Cancer. 2010;62(3):329-35.

26. Briviba K, Bub A, Moseneder J, Schwerdtle T, Hartwig A, Kulling S, et al. No differences in DNA damage and antioxidant capacity between intervention groups of healthy, nonsmoking men receiving 2, 5, or 8 servings/day of vegetables and fruit. Nutr Cancer. 2008;60(2):164-70.

27. Pedersen M, Schoket B, Godschalk RW, Wright J, von Stedingk H, Tornqvist $\mathrm{M}$, et al. Bulky DNA adducts in cord blood, maternal fruit-and-vegetable consumption, and birth weight in a European mother-child study (NewGeneris). Environ Health Perspect. 2013;121(10):1200-6.

28. Rice-Evans CA, Miller NJ. Antioxidant activities of flavonoids as bioactive components of food. Biochem Soc Trans. 1996;24(3):790-5.

29. Leonard SS, Cutler D, Ding M, Vallyathan V, Castranova V, Shi X. Antioxidant properties of fruit and vegetable juices: more to the story than ascorbic acid. Ann Clin Lab Sci. 2002;32(2):193-200.

\section{Submit your next manuscript to BioMed Central and take full advantage of:}

- Convenient online submission

- Thorough peer review

- No space constraints or color figure charges

- Immediate publication on acceptance

- Inclusion in PubMed, CAS, Scopus and Google Scholar

- Research which is freely available for redistribution 